\title{
A clausura feminina no mundo ibero- atlântico: Pernambuco e Portugal nos séculos XVI ao XVIII
}

Suely Creusa Cordeiro de Almeida ${ }^{1}$

Garantir a proteção da prole feminina sempre foi uma preocupação das famílias no mundo ibero-atlântico do Antigo Regime. Quando não era possível casar as moças com pessoas de qualidade, buscar o abrigo das casas de clausura para dar-lhes um estado foi uma opção e, em muitos casos, uma demonstração de afeto dos genitores. Os espaços de clausura assumiram múltiplas funções, pois tanto permitiam a almejada proteção e honra como possibilitavam uma vida devota para aquelas que tinham vocação. Mas, contraditoriamente, se constituíram em espaços de prisão para aquelas que de alguma forma romperam as fronteiras dentro das quais era permitido às mulheres se movimentarem. Assim, neste artigo tentamos demonstrar como as instituições de clausura fizeram parte do cotidiano das mulheres e das famílias fidalgas da sociedade do Antigo Regime.

Palavras-chave: mulher, nobreza, clausura, ibero-atlântico.

Female Cloister in the Ibero-Atlantic World: Pernambuco and Portugal in the sixteenth to the eighteenth century

To ensure the protection of female brood was always a concern for families in IberoAtlantic world of the Old Regime. When it was not possible to marry the girls with quality people, seek the shelter of the cloister houses to give them a state was an option and, in many cases, a demonstration of affection of the parents. The cloistered spaces assumed multiple roles, as both allow the desired protection and honor, as a devout life made possible for those who had a vocation. But, in contradiction, make up

\footnotetext{
${ }^{1}$ Professora da Graduação e da Pós-graduação em História da Universidade Federal Rural de Pernambuco.
} 
prison space for those who somehow broke the boundaries within which women were allowed to move. Thus, this paper tries to demonstrate how cloistered institutions were part of the life of women and families of aristocratic society of the Ancien Regime. Keywords: Women, Nobility, Cloister, Ibero-Atlantic

\section{La claustration féminine dans le monde Ibéro-Atlantique: Pernambouc et Portugal aux XVIe et XVIIIe siècles}

Assurer la protection de la descendance féminine a toujours été une préoccupation des familles du monde ibéro-atlantique sous l'Ancien Régime. Lorsqu'on ne pouvait pas marier les jeunes femmes avec des gens de bien, les mettre à l'abri dans des maisons de claustration pour leur offrir une condition constituait une option possible et, dans bien des cas, une manifestation d'affection de la part des géniteurs. Les espaces de claustration possédaient de multiples fonctions ; ils permettaient de garantir cette protection tant recherchée et de préserver leur honneur, tout en donnant la possibilité de mener une vie de dévotion à celles qui en avaient la vocation. Mais de manière contradictoire, ils devinrent des espaces de captivité pour celles qui, d'une manière ou d'une autre, rompaient les frontières à l'intérieur desquelles les femmes avaient le droit de se mouvoir. Ainsi, dans cet article, nous essaierons de démontrer comment la claustration institutionnalisée faisait partie du quotidien des femmes et des familles de la société de l’Ancien Régime.

Mots-clé: Femme, Noblesse, Claustration, Ibéro-atlantique

Este trabalho pretende refletir sobre a condição das mulheres consideradas de qualidade, ${ }^{2}$ filhas da nobreza da terra residentes na capitania de Pernambuco no período denominado colonial e que foram encaminhadas para a clausura tanto em Pernambuco como em Portugal. Nesse contingente feminino, englobaremos as solteiras, casadas e viúvas que foram enclausuradas por suas famílias por vontade ou imposição. Não discutiremos o ardor da fé, no sentido de apontar experiências de vocação religiosa, abordaremos apenas os aspectos social e familiar da vida religiosa, já que ser religiosa era um estado ${ }^{3}$ possível e desejável para as mulheres fidalgas e para suas famílias. Apresentaremos as histórias de clausura sem analisar em pormenores sua acepção institucional, ou seja, arrolaremos conventos e recolhimentos como casas onde foi possível às mulheres viverem segundo os ditames das sociedades ibéricas.

\footnotetext{
2 "Qualidade: A essência da coisa. É um acidente absoluto, que aperfeiçoa a substância assim no obrar como no ser” (BLUTEAU, Raphael. Vocabulário português \&ُ latino: áulico, anatômico, architectonico... Coimbra: Collégio das Artes da Companhia de Jesus, 1728. v. 7, p. 9).

3 "Estado: Condição de uma pessoa. Gênero de vida, modo de viver, profissão" (BLUTEAU, Raphael. Op. cit., v. 3, p. 301-302.
} 
Há, para a história das mulheres no Pernambuco colonial, em especial, da clausura feminina, um óbice: a escassez das fontes. Elas não foram preservadas nos arquivos locais. Nos Avulsos de Pernambuco depositados no Arquivo Histórico Ultramarino há, no entanto, indícios da presença feminina em ofícios, requerimentos e petições os mais diversos. Ora elas são alvo de comentários, ora ditam ao notário suas vontades. Também é possível encontrar referências sobre o gênero feminino em alguns cronistas e viajantes que andaram pela capitania. Mas, em quase sua totalidade, essas fontes são indiretas, filtradas pela visão das autoridades masculinas. Essa documentação fragmentária e sem continuidade torna muito difícil uma análise quantitativa do tema. Por outro lado, o Arquivo da Cúria Metropolitana do Recife e de Olinda não preservou a documentação do Tribunal Eclesiástico, impedindo que tivéssemos acesso às sindicâncias movidas pelo bispado para toda mulher que fez pedido para se enclausurar no Reino depois de $1732,{ }^{4}$ data em que D. João V, por alvará, passou a proibir a saída de mulheres do Brasil com destino à clausura no Reino sem a devida avaliação e autorização do bispado e do governador da capitania. Diante do exposto, os dados e a reflexão que apresentamos foram construídos a partir do paradigma indiciário, aproximando os poucos registros deixados no sentido de formar um corpus documental que tornasse o tema inteligível.

Dar estado às mulheres de qualidade foi uma preocupação constante da monarquia portuguesa. Essa prática está ligada a toda uma concepção de caridade, mas também envolta na ideia de que era necessário garantir a manutenção da condição $o^{5}$ daqueles que haviam nascido nobres. Presumia-se que os nascidos em berço aristocrático estavam em um patamar mais elevado na "cadeia do ser", segundo Arthur O. Lovejoy. Em sua natureza - e aí entenda-se em uma perspectiva divina da plenitude -, teriam sido formados por elementos mais refinados, demonstrando, inclusive, uma gradação. Assim, defendê-los da miséria era dever daqueles que detinham condições materiais para garantir a manutenção

\footnotetext{
${ }^{4}$ Biblioteca Nacional de Lisboa - Papéis Avulsos - Resolução de D. João V - 7/8/1727.

5 "Condição: Estado em que alguém ou alguma coisa se acha. Lugar que uma pessoa tem no mundo" (BLUTEAU, Raphael. Op. cit., v. 2, p. 448-449).
} 
da ordem estabelecida e a hierarquia das criaturas, princípios criados não pelos homens em primeira mão, mas por Deus. ${ }^{6}$

No caso das mulheres ainda mais, pois estavam situadas em um grupo que precisava de proteção extra. Segundo a tradição, Eva cedera à sedução de Satanás no Éden, demonstrando o quão frágeis eram esses seres criados da costela de Adão. ${ }^{7}$ Carregando essa pecha, as mulheres foram incluídas na legislação do Reino entre o grupo dos simples, rústicos e imbecis, ou seja, aqueles que, por falta de tino, deveriam ser tutelados. ${ }^{8}$ Tornou-se, então, um dever para o Estado e para os homens, fossem pais, maridos, irmãos, tios ou filhos, protegê-las, muitas vezes com o argumento de que as livravam delas mesmas, para que com essa prática chegassem à bem-aventurança, preservando a boa sociedade. O Livro $\mathrm{V}$ das Ordenações Filipinas explicitava que uma mulher não podia ser presa por dívidas, representar-se, ser fiadora, suceder, gozar de atenuantes quanto à aplicação das penas ou ser admitida nos cargos públicos. Em outras palavras, não havia legalmente oportunidade para a mulher exercer plenamente qualquer representação jurídica. O casamento não a emancipava, e ao marido era permitido castigar moderadamente sua esposa e até matá-la se a surpreendesse em adultério. Contribuíam para o sustento do lar por meio do dote, embora estivessem, teoricamente, privadas de administrar seus bens, prerrogativa unicamente masculina, mesmo que a historiografia atual já esteja a relativizar essa dependência e submissão em muitos aspectos. ${ }^{9}$ Em uma sociedade em que o aparentar ser valia mais do que o ser, as mulheres que eram bem-nascidas tiveram de lutar por toda a vida

\footnotetext{
${ }^{6}$ Cf. LOVEJOY, Arthur Onck. A grande cadeia do ser: estudo da história de uma idéia. São Paulo: Palíndromo, 2005; FERREIRA, Fátima Sá Melo. Conceito de ordem em Portugal (séculos XVIII e XIX). Revista Tempo, v. 16, n. 31, p. 21-34, jul./dez. 2011.

${ }^{7}$ DUBY, George. Eva e os padres. São Paulo: Companhia das Letras, 2001, passim.

${ }^{8}$ HESPANHA, António Manoel Botelho. Imbecillitas: as bem-aventuranças da inferioridade nas sociedades do Antigo Regime. São Paulo: Annablume/Capes/Escola de Altos Estudos, PPGH/ UFMG, 2010, passim.

${ }^{9}$ HESPANHA, António Manoel Botelho. Direito luso-brasileiro no Antigo Regime. Florianópolis: Fundação Boiteux, 2005. p. 64; MENEZES, Jeanne da Silva. Sem embargo de ser fêmea: as mulheres e um estatuto jurídico em movimento no direito local em Pernambuco no século XVIII. Tese (Doutorado em História) - Universidade Federal de Pernambuco, Recife, 2010. p. 129 e 135.
} 
para manter esse lugar, fosse por meio dos bens materiais ou dos imateriais, como a honra, preservando a boa fama. ${ }^{10}$

A honestidade e a reclusão, não necessariamente a conventual, foram desejáveis como comportamento idealizado para as mulheres. Do Direito às obras literárias, uma imagem de pureza perpassou todo o imaginário moderno, configurando-se na representação desejável para o sexo frágil. Atender a uma imagem esperada, advogar honestidade e boa fama, cumprir as etiquetas e os preceitos cerimoniais, incorporar os discursos elaborados, os elementos esperados de uma cultura laica e religiosa foram estratégias usadas pelas mulheres para atingir seus objetivos junto aos tribunais ou às instituições portuguesas em geral. Saliente-se que ser honesta ligava-se à manutenção da virgindade e do luto após a viuvez.

A conquista de um estado, na trajetória feminina, representava estar incluída na boa sociedade. Hespanha define os estados como sendo de cristã casada e religiosa. Embora tenham chegado a um desses lugares, o medo de perdê-lo sempre roubou o sono às fidalgas. ${ }^{11}$ Privar-se da tutela familiar, ter de agenciar a sobrevivência trabalhando com as mãos e até se prostituir tornaram-se um grande fantasma. Foi para aplacar essa tensão entre ter qualidade e perder a condição que instituições como os conventos e os recolhimentos foram fundados no Reino e nas conquistas. Eles surgiram ligados as mais diversas regras em vilas e cidades para dar estado às mulheres brancas e bem-estimadas.

Os recolhimentos serviram para viabilizar um lugar para aquelas que estavam perdendo a condição ou a honra, quando não as duas coisas, em locais onde não havia casas canonicamente instituídas. ${ }^{12}$ Para remediar situações já impostas, ou para prevenir, os recolhimentos foram sempre uma saída à mão das famílias em geral, pois é mais do que sabido que um mau passo dado por mulheres importantes, fora das normas ou dos comportamentos idealizados, seria uma mácula para toda uma linhagem familiar, impedindo principalmente os homens de se incluírem nas elites locais. Então, como já dissemos, as histórias de vida que ana-

\footnotetext{
${ }^{10}$ PEREIRA, Nuno Marques. Compêndio narrativo do peregrino da América. 7. Ed. Rio de Janeiro: Academia Brasileira de Letras, 1968; DELICADO, António. Adágios portugueses reduzidos a lugares- comuns. Porto: Tip. Sociedade de Papelaria, 1923.

${ }^{11}$ HESPANHA. Op. cit., p. 65.

${ }^{12}$ Convento: Casa de clausura reconhecida canonicamente. Recolhimento: Casa de clausura leiga, sem exigência de votos (ALMEIDA, Suely Creusa Cordeiro de. O sexo devoto: normatização e resistência feminina no Império português, XVI-XVIII. Recife: Universitária/UFPE, 2005. p. 129-137).
} 
lisaremos a seguir serão contadas incluindo as instituições, convento e recolhimento, embora conscientes das diferenças entre ambos, entendendo que, no que tange à clausura imposta ou não às mulheres, eles foram espaços de realização de um projeto social para a mulher no mundo ibero-atlântico. ${ }^{13}$

Para recolher uma filha em casa de clausura era necessário um cabedal significativo. Pagava-se o dote à instituição, providenciava-se a viagem atlântica, além de se exigir do pleiteante certo prestígio para conseguir uma vaga. As opiniões em Pernambuco se dividiam: algumas famílias advogavam a necessidade de enclausurar suas filhas em nome da preservação dos bens da família, de não ver suas propriedades divididas e levados os recursos para o Reino, e consideravam que seria melhor pagar as despesas de travessia e o dote ${ }^{14}$ a um convento do que casá-las. Outras famílias apontavam as despesas transatlânticas e o dote pago às instituições como vultosos, advogando a ereção de convento em Pernambuco que pudesse acolher as filhas das famílias nobres, sem que para isso necessitassem sofrer o trauma do traslado para o Reino nem o dispêndio de grandes recursos. Havia necessidade de parentes próximos acompanharem as pleiteantes à reclusão. Era uma situação bastante incômoda, pois afastava durante meses os homens dos negócios da família até que se completassem a travessia marítima e a instalação da moça na casa adequada aos recursos disponíveis, para que os acompanhantes pudessem retornar à colônia. Aliás, os perigos da travessia eram um argumento muito utilizado para advogar a instalação de conventos em Pernambuco. $\mathrm{O}$ afastamento quase que total das moças de suas famílias também desestimulava a opção pelo Reino, sobretudo quando não havia parentas enclausuradas nas casas escolhidas.

Aqui, é necessário fazer uma ponderação. Não se deve imaginar que a atitude das famílias buscando enclausurar suas filhas fosse uma demonstração de desinteresse para com a prole feminina. Não, pelo contrário. Pais e mães demonstravam cuidado para com suas filhas, tanto que estavam preocupados em dar-lhes as melhores condições que suas posses pudessem permitir, pois as alternativas que não fossem o casamento ou a clausura institucional não eram bem vistas para

\footnotetext{
${ }^{13}$ Idem.

${ }^{14}$ Dote: Bens concedidos a uma pessoa, ou levados quando da viuvez (NAZZARI, Muriel. O desaparecimento do dote: mulher, famílias e mudança social em são Paulo 1600-1900. São Paulo: Companhia das Letras, 2001. p. 15-19).
} 
mulheres fidalgas. Ambas as experiências, enclausurar no Reino ou em Pernambuco, foram vividas ao longo do período colonial. Seguindo a narrativa, pretendemos esclarecer os caminhos trilhados e as opções feitas pelas famílias da elite pernambucana.

\section{A nobreza da terra e os recolhimentos no Pernambuco colonial}

Já no século XVI, houve uma tentativa de fundar uma casa de clausura feminina na capitania de Pernambuco. Os jesuítas, preocupados com a educação das filhas mestiças dos fidalgos portugueses com as nativas, fundaram um embrião de recolhimento por volta de 1560. Essa instituição ficou sob o encargo da mesa regedora da Irmandade de Nossa Senhora da Conceição e passou a chamar-se Recolhimento de Nossa Senhora da Conceição, funcionando na vila de Olinda. As informações mais precisas sobre a casa remontam a 1585, quando a Irmandade, em reunião, decidiu lavrar escritura de sua igreja com mesma invocação mais algumas casas a ela contíguas e terrenos anexos, que eram utilizados para serviço da confraria, doando-as à terceira regular D. Maria da Rosa, matrona nascida no Reino e abastada viúva de Pedro Leitão, momento esse em que teria transformado as edificações existentes em recolhimento.

As instalações foram ampliadas às suas custas, obtendo a cooperação financeira de amigas e companheiras que já envergavam o hábito da Ordem Terceira de S. Francisco ${ }^{15}$ que com ela ali se recolheram. A partir de então, transferiu-se do retiro de Nossa Senhora das Neves, também por ela fundado e onde já vivia reclusa desde que enviuvara, doando a propriedade aos franciscanos que chegavam a Pernambuco para instalarem no lugar a Custódia de Santo Antônio do Brasil. A Irmandade de Nossa Senhora da Conceição, umas das primeiras erigidas no Brasil e que congregava gente de qualidade, amparou as recolhidas de Nossa Senhora das Neves, trazendo-as para habitar no espaço físico pertencente

\footnotetext{
${ }^{15}$ Segundo frei Jaboatão, foi fundada por Gaspar Figueira, congregação que atraiu a nobreza da terra, inclusive Maria Rosa (JABOATÃO, Fr. Antonio de Santa Maria. O novo orbe seráfico brasílico ou crônica dos frades menores da província do Brasil. Recife: Assembleia Legislativa do Estado de Pernambuco, 1980. p. 385).
} 
à confraria com promessa de construírem mosteiros ou conventos para religiosas professas, sonho que foi acalentado por séculos. ${ }^{16}$

A história da fundação do Recolhimento de Nossa Senhora da Conceição em Olinda foi contada principalmente por dois cronistas e um historiador. Aqui nos referimos a D. Domingos Loreto Couto e frei Antonio de Santa Maria Jaboatão, cronistas eclesiásticos do século XVII, e ao historiador pernambucano do século XIX Francisco Augusto Pereira da Costa. Além desses, incorporamos em nossa análise o Livro 1 do Recolhimento de Nossa Senhora da Conceição em Olinda, que, embora seja do século XIX, recupera, em suas páginas iniciais, a trajetória da casa e os Avulsos de Pernambuco depositados no Arquivo Histórico Ultramarino. ${ }^{17}$

Segundo D. Domingos, a casa também foi tutelada pela família de Jerônimo de Albuquerque, o Torto, e Felipa de Melo, em finais do século XVI. A família investiu vultoso cabedal para nela recolherem suas filhas, que se chamavam Izabel, Cosma e Luiza de Albuquerque, representantes da nobreza da terra, todas naturais de Olinda. A fundação do recolhimento das Albuquerques provavelmente se deu entre 1584 e 1593, data provável da morte do patriarca da família. Lá viveram uma vida de religiosas professas sem o serem. Sua reclusão foi cercada de conforto e pompa, como demonstra a solicitação feita por D. Izabel de Albuquerque $^{18}$ aos beneditinos de Olinda em 1608. Ela desejava ser sepultada, juntamente com seus pais, Jerônimo de Albuquerque e D. Cosma, no mosteiro dos beneditinos. Para tanto, doou todos os seus bens, ficando até a sua morte apenas com seis escravos da Guiné, que a serviam no recolhimento, além do que

\footnotetext{
${ }^{16}$ A Irmandade de Nossa Senhora da Conceição passa todo o patrimônio - casa e igreja - para D. Maria Rosa e para as demais recolhidas até a morte delas, ou enquanto estivessem recolhidas. Na falta delas, o patrimônio retornaria à Irmandade. Tomaram posse com a aquiescência de: Martin Leitão (ouvidor-geral da capitania de Pernambuco e juiz dos resíduos e capelas), D. Antonio Barreiros (bispo de Pernambuco). Cúria Metropolitana do Recife e Olinda - CMRO - Livro 1 - Recolhimento de Nossa Senhora da Conceição de Olinda - 1820-1862. Ver, também: JABOATÃO, Fr. Antonio de Santa Maria. O novo orbe seráfico brasílico ou crônica dos frades menores da província do Brasil. Recife: Assembleia Legislativa do Estado de Pernambuco, 1980; COUTO, Domingos Loreto. Desagravos do Brasil, glórias de Pernambuco. Recife: Fundação de Cultura da Cidade do Recife, 1984; COSTA, Francisco Augusto Pereira. Anais pernambucanos. Recife: Secretaria de Cultura, 1980. v. 1.

${ }^{17}$ CMRO - Livro 1 - Recolhimento de Nossa Senhora da Conceição de Olinda - 1820-1862.

${ }^{18}$ Izabel de Albuquerque não era filha de D. Felipa de Melo, mas de uma mulher chamada Cosma. Ver: COUTO. Op. cit., p. 495.
} 
repassava as dívidas que os beneditinos tinham consigo para a construção de uma capela colateral das grades de dentro, dedicada a Nossa Senhora do Pilar, para sua sepultura. Essa capela, contudo, não lhe serviu de último abrigo, pois, na altura da invasão holandesa, D. Izabel fugiu para a Bahia, lugar em que veio a falecer. ${ }^{19}$

Também viveram no Recolhimento de Nossa senhora da Conceição as fidalgas e irmãs Maria de Mendonça e Madalena Furtada. Eram filhas do mestre de capela Gomes Correia e recolheram-se com mais de 25 anos. Em 1615, eram herdeiras de terras, 800 braças em Macaipe, recebidas como dote, depois de firmado o compromisso de investirem parte no refrigério das almas de seus pais. $\mathrm{O}$ patrimônio, que depois foi vendido aos monges de São Bento pela quantia de 120 mil réis, foi aplicado em $50 \%$ dos recursos na celebração de missas pela alma de seus genitores. ${ }^{20}$

As irmãs Maria da Trindade e Ana de Melo Barreto, ambas naturais do Cabo de Santo Agostinho, filhas de Cristóvão Paes Barreto e Margarida de Melo, ofertaram seus cabedais para o sustento da casa, vivendo dedicadas aos exercícios espirituais até a morte de ambas, que provavelmente ocorreu em $1626 .{ }^{21}$ Era família de muitas posses, aparentada dos senhores do morgado do Cabo, região inclusa no Termo de Olinda e que distava desta quase seis léguas. Antes de morrer, as recolhidas doaram todos os seus bens ao recolhimento, com o compromisso de serem sepultadas na igreja de Nossa Senhora da Conceição, contígua à casa.

Com a invasão holandesa, o recolhimento foi destruído, voltando a ser restaurado e habitado depois de 1654. Em seu percurso ao longo dos séculos XVII e XVIII, viveu fases de decadência e relaxação; no entanto, nunca deixou de receber recolhidas das melhores famílias pernambucanas, fosse por falta de dote, vocação ou mau comportamento. Ainda no século XVII, recebeu a tutela do casal João Fernandes Vieira e Maria Cezar, provedor da Santa Casa de Misericórdia. A tutela deu-se só depois de perder a validade o acordo feito entre a irmandade de Nossa Senhora da Conceição e D. Maria Rosa. Por meio da Santa Casa de Misericórdia, João Fernandes Vieira amparou o projeto de sustentar e restaurar

\footnotetext{
${ }^{19}$ COSTA. Op. cit., v. 1, p. 552-556.

${ }^{20}$ Ibid., v. 2, p. 28.

${ }^{21}$ Ibid., v. 1, p. 554.
} 
o recolhimento; no entanto, embora tivesse prestígio e riqueza, não conseguiu transformá-lo em mosteiro de freiras professas. ${ }^{22}$

No final do Seiscentos, D. Antonia de Souto, viúva do governador Francisco de Figueroa, doou seus bens ao recolhimento: casas e senzalas no bairro do Recife e um engenho de açúcar na Paraíba. Para recebê-los, o recolhimento deveria mandar rezar missas diárias em sua intenção, além de providenciar uma sepultura na capela-mor da igreja da Conceição. ${ }^{23}$ Essas doações e tutelas mantiveram o recolhimento em funcionamento, embora os depoimentos do bispo D. José Fialho, do início do Setecentos, tenham pintado um quadro de abandono e desordem. Ele revelou que a casa passou a receber mulheres por mau comportamento, que adentraram inclusive grávidas, provocando escândalo em Olinda e em Recife. ${ }^{24}$

No século XVII, algumas fidalgas pernambucanas se recolheram em Olinda por mau comportamento. Essa escolha do Recolhimento de Nossa Senhora da Conceição pelas famílias nobres da terra, mesmo com o objetivo de castigar as recalcitrantes, comprova a tradição da casa em abrigar as filhas da açucarocracia pernambucana. Duas trajetórias femininas, extraídas de documentação depositada no Arquivo Histórico Ultramarino, iluminam a história dessa casa, considerada nobre, que almejou ser convento professo durante todo o período colonial.

A primeira chamava-se Brites Manoela, moça de família de qualidade pertencente ao clã de Estevão Paes Barreto, seu irmão e sétimo morgado do Cabo. Brites conheceu, em meados do século XVIII, João de Rego Barros, homem também poderoso na capitania, que, com palavras doces e afagos, falou-lhe de amores. Acreditando Brites em suas carícias e promessas, a ele entregou-se apaixonada, imaginando que em seguida seria dada em casamento, haja vista não haver impedimento social para tal. Mas João do Rego Barros, homem experimentado e famoso por suas conquistas amorosas, abandonou Brites grávida de um filho seu. Mas a fidalga não se calou, nem escondeu a desonra, denunciou seu amante à família, que, indignada, incitou-a a mover contra ele um processo por meio do Conselho Ultramarino. Todo o sucedido foi narrado e enviado ao Reino, que

\footnotetext{
${ }^{22}$ ALMEIDA. Op. cit., passim. Ver, também: MELLO, J. A. G. de. João Fernandes Vieira - mestre de campo do Terço de Infantaria de Pernambuco. Recife: Imprensa Oficial, 1956.

${ }^{23}$ COUTO. Op. cit., p. 514.

${ }^{24}$ ALMEIDA. Op. cit., passim.
} 
decidiu pela reparação da honra de Brites pelo casamento. João casou-se com Brites, mas o afeto de antes transformou-se em ressentimento e ódio. Nunca viveram juntos, e ela confinou-se na casa dos pais, impedida de um novo casamento.

Vida amargurada, sem alegrias, vigiada pelos parentes próximos, que perderam a confiança em sua pessoa, cercada por irmãs casadas que constituíram família, enquanto ela vegetava e via esvair-se a juventude na solidão. Ele voltou à sua vida normal de homem poderoso e abastado, vivendo dissolutamente nos anos subsequentes na vila de Recife. Os anos se passaram. Mortos o marido e seus pais, Brites resolveu dar um novo rumo à sua vida saindo da casa de seu irmão e montando para si uma casa na vila de Recife. Levou consigo alguns escravos e passou a viver livremente, recebendo pessoas em sua casa sem levar em consideração sua qualidade e condição. Essa vida de liberdade envergonhou toda a família, tornando-se assunto de toda a capitania. Viam-se vexados e cobertos de ignomínia pelo comportamento vulgar de Brites. Estevão Paes Barreto, indignado ainda mais pelo confisco de escravos de seu plantel pela irmã, moveu um processo contra ela, por meio do Conselho Ultramarino, acusando-a, entre outras coisas, de prostituição. Pediu à rainha $\mathrm{D}$. Maria I para recolhê-la no Recolhimento de Nossa Senhora da Conceição, com impedimento de não poder sair sem seu consentimento. Sua petição foi atendida; Brites foi enclausurada e seus bens confiscados, sendo, em parte, destinados para sua alimentação intramuros. ${ }^{25}$

Outra fidalga cruzou os muros do nobre recolhimento de Olinda como alguém que vai para uma prisão. Seu nome? Isabel dos Reis. Seu crime? Desejar casar-se com Manoel José Vianna, homem inferior a si em qualidade. Enamorados, ambos enfrentaram a negativa da família de Isabel, que tinha à sua testa a viúva D. Ana Ferreira Maciel. Segundo a viúva, Manoel José tinha um único interesse: tirar vantagem econômica dos bens da família que se encontravam em inventário. Ele era considerado indigno, pela consanguinidade, de se introduzir no seio de uma honrada família. Para justificar sua abominação pelo casamento, Ana se expressa sobre o pretenso noivo da seguinte forma:

Incapaz de imiscuir-se em sua família, que é de reconhecida nobreza e de notória probidade [...] filho de Antonio José Vianna, moço que foi de servir; depois caixeiro, e ultimamente lojista de retalhos, [...] foi casado com Anna Joaquina Coelha, adúltera com pública notoriedade, a qual foi compreendida em fragrante delito, e denun-

${ }^{25}$ AHU - Avulsos de Pernambuco - Cx. 146, Doc. 10661 - 7/12/1782. 
ciada pelo seu dito cônjuge, depois de cujo falecimento perseverou prostituta e neto de barqueiro [...], e bisneto de carpinteiro [...] insidioso de fazer-se participante dos bens do casal da suplicante [...].26

A condição subalterna de Manoel, oriundo de uma família que tratava de trabalhos manuais, ou seja, possuía o defeito mecânico, provavelmente mestiço, assim impuro de sangue, colocava o casamento fora de cogitação no seio de uma família que se considerava nobre e limpa.

Isabel ainda não chegara aos 25 anos, portanto, pelas Ordenações Filipinas, era considerada menor, estando totalmente sob a tutela da família, não podendo tomar a decisão de se casar. Para contornar a situação, Manoel procurou apoio junto ao juiz de fora e órfãos, Manoel de Macedo Pereira Coutinho da Horta, que realizava o inventário dos bens da família de Isabel. Apiedado da situação de impedimento vivida pelo casal, o juiz de fora tentou intimidar a mãe da moça retendo o andamento do inventário. Recebendo uma negativa e ofendido em seu prestígio, o juiz dispôs-se a realizar o casamento, e para tal contou com o apoio do ouvidor-geral, corregedor da comarca e governador da capitania, para cujo projeto conquistou e não envidou esforços, inclusive econômicos.

Por sua vez, Isabel concordou em ser depositada na casa de Domingos Afonso Ferreira, sequestro implementado pelo juízo da ouvidoria, que esperava conseguir a emancipação de Isabel, a antecipação dos 25 anos, para que pudesse livremente casar-se com Manoel José.

Na casa de Domingos Afonso, Isabel sentia-se livre, podia colocar-se à janela, correspondia aos acenos do amado, que estava sempre à porta da botica de Francisco Sampaio. Isabel podia ir à missa sozinha, na capela de Nossa Senhora da Conceição da ponte do Recife, indo, ainda, acompanhada do casal que a acolhia a divertimentos em Ponte de Uchoa e Boa Vista, estando à vontade para assistir às procissões na rua, tudo também em companhia de Manoel José Vianna, embora ainda não estivessem casados nem vivendo como tal.

Finalmente, como não conseguiram autorização para realizarem o casamento, resolveram o juiz de fora e Manoel forjar um despacho, imitando a letra do vigário-geral, no qual este concedia licença para que Manoel se casasse com Isabel, sendo auxiliado nisso pelo padre José Ignácio Ribeiro, que foi o celebrante da

${ }^{26}$ AHU - Avulsos de Pernambuco - Cx. 189, Doc. 13065 - 13/8/1795. 
cerimônia. Os enamorados casaram-se na capela de Nossa Senhora da Conceição das Barreiras, no sítio de Domingos Afonso Ferreira. Inconformada com a desobediência da filha, Ana Ferreira Maciel imediatamente impetrou uma devassa para apurar a autenticidade do despacho de casamento, sendo, para tal, arroladas 30 testemunhas favoráveis ao embargo e que foram ouvidas na casa do vigáriogeral e juiz dos casamentos e resíduos, Dr. Manoel Xavier Carneiro da Cunha.

Enquanto isso, Isabel e Manoel, nos dias que se seguiram ao casamento, viviam idilicamente. Conta-nos a testemunha Casimiro Antonio de Medeiros que estavam " $[. .$.$] os nubentes assistindo juntos unidos de portas adentro em$ uma casa de sobrado no curtume do Fundão que se acha alugada por conta do Juiz de Fora Manoel de Macedo Pereira Coutinho [...] para nela residirem depois de casarem [...]". ${ }^{27}$ Lá fora, o povo comentava o escandaloso caso. Uma moça de família saíra de casa, fora várias vezes vista em companhia de um homem, que nem era seu pai, irmão ou marido, e ainda mais rumores de que tinha contraído matrimônio, acobertado com um falso despacho do Juízo Eclesiástico. Todos esses acontecimentos provocaram um grande escândalo para a família Maciel. Procurava-se o autor do crime de falsificação, o qual foi apontado pelo presbítero secular Veríssimo Machado Freire como sendo Ignácio da Fonseca Neves.

O desenrolar do processo foi doloroso. Uma vez concluído, deixou um saldo de amargura e dor. Depois de ouvidas as testemunhas arroladas, examinados os autos e todos os mais documentos, com certidões, cartas particulares e cartas patentes, concluiu-se que os contraentes Manoel José Vianna e D. Isabel Maria dos Reis não se achavam validamente casados e deveriam ser tidos por solteiros, livres e desimpedidos, por terem contraído um matrimônio inteiramente nulo e de nenhum valor e daqueles que, em Direito, se denominam clandestinos.

O Juízo Eclesiástico, em autos lavrados, considerou os contraentes inabilitados para casar por impedimento civil, pois a mãe da contraente impôs embargos para que as núpcias acontecessem. Por fim, o tribunal decidiu que, mesmo solteiros, podendo contrair matrimônio com outra pessoa, se tornavam os contraentes, por essa sentença, "inabilitados para contraírem de novo entre si, visto o dolo, e malícia com que os fizeram [...]”. ${ }^{28} \mathrm{E}$, finalizando sua sentença, considerou todos os envolvidos' com exceção do juiz de fora, como culpados, devendo ser

\footnotetext{
${ }^{27}$ AHU - Avulsos de Pernambuco - Cx. 189, Doc. 13065 - 13/8/1795.

${ }^{28}$ AHU - Avulsos de Pernambuco - Cx. 189, Doc. 13065 - 13/8/1795.
} 
presos. Os enamorados deveriam ser separados, além de excomungados e presos. Concluído tudo, Ana Maciel, em gozo de sua autoridade de matriarca, pede a D. Maria I que "sua mísera filha [...] seja logo e para sempre ingressa e selada no Recolhimento de Nossa Senhora da Conceição da cidade de Olinda, e donde jamais possa sair ou ser extraída [...]". ${ }^{29}$

Fora da conquista e seguindo as rotas atlânticas, é possível apresentar alguns casos de jovens que foram enviadas para conventos em Portugal.

\section{Mulheres de Pernambuco nos conventos do Reino}

Nesses casos, era o pai que, por meio de uma carta, apresentava as condições da aspirante à freira. Foi dessa forma que procedeu João Lopes Barros, natural da Vila do Recife, pai de D. Francisca Xavier de Jesus Maria, que manifestava desejo de se recolher em um dos conventos da Ilha Terceira, da cidade de Angra. A moça é apresentada como uma donzela cheia de dons. Era solfista, organista e harpista, estava com a idade de 16 anos, já sendo capaz de professar. Anexa à carta do pai, encontra-se outra da própria Francisca, na qual expôs seu desejo de servir a Deus. O Conselho Ultramarino acionou o Juízo Eclesiástico para que procedesse a uma investigação, tanto junto à candidata quanto às pessoas ligadas a ela e à família. No atestado redigido pelo juiz eclesiástico sobre as averiguações feitas, consta que "voluntariamente Francisca Xavier desejava ser religiosa e que, para esta sua resolução, não teria havido coação nem violência alguma, e que, nesta vocação, persistia já há anos, no que também me certifiquei por informações particulares". ${ }^{30}$

O governador de Pernambuco colocou-se, no entanto, totalmente contra a ida de D. Francisca para recolhimento na Ilha Terceira e, em seu parecer, considerava que, com as despesas que faria o pai enviando a filha para Angra, poderia casá-la muito bem. Apesar da oposição da autoridade laica da capitania, o Conselho Ultramarino foi favorável à licença.

O que chama a atenção nos depoimentos é a grande preocupação em asseverar que as moças não estavam sendo coagidas a recolherem-se em conventos pelos familiares. As autoridades laicas persistiam no argumento de que, se havia

\footnotetext{
${ }^{29}$ Idem.

${ }^{30}$ AHU - Avulsos de Pernambuco - Cx. 49, Doc. 4387 - 7/5/1736.
} 
recursos financeiros, era possível providenciar um casamento, sendo desnecessário recolhê-las no Reino. Por sua vez, o Juízo Eclesiástico sempre agiu com muita cautela em relação à questão da vocação das pretendentes, inclusive quanto ao fato de muitas terem pouca idade para optarem pelo estado de religiosas, embora admitamos que os sete anos eram o portal para a passagem à idade da razão. Essa preocupação pode ser um indicador de que uma parcela significativa das moças se recolhia contra a vontade. Acreditamos que um grande número de petições foi resultante de situação familiar desfavorável ao matrimônio, provocando um pipocar de muitos escândalos envolvendo reclusas sujeitadas às regras de clausura, associada à tendência reformadora das ordens religiosas, que passaram a ser mais rigorosas na hora de receber uma pleiteante. Tudo isso motivou sindicâncias do Juízo Eclesiástico, como também posições reticentes dos governadores, muito embora estes estivessem mais preocupados em atender à política real, que era a de impedir a saída de mulheres solteiras para conventos e, consequentemente, promover o povoamento das conquistas, tema insistente na documentação produzida entre o reinado e D. João V e D. José I.

Mas, nem tanto ao mar, nem tanto à terra. Apesar de grande parte dos trabalhos já publicados sobre a vida conventual se dedicar a mostrar a imposição de uma situação de clausura, é evidente que uma parte do contingente de moças que se recolheram, quer em Portugal, quer no Brasil, o fez motivada pela vocação ou por um processo cultural que apresentava o recolhimento como algo perfeitamente natural. O exemplo que apresentamos a seguir demonstra o quão natural poderia ser a possibilidade da reclusão para uma parte do contingente feminino de uma família colonial.

O homem de negócios Manoel Alves Ferreira, atuante na praça do Recife, por meio de sua carta ao rei D. João V, traz à luz os argumentos e as contingências que levaram famílias luso-pernambucanas a optarem pelo destino da reclusão conventual para uma parte de sua prole feminina. Por meio da petição lavrada em cartório, ele conta que teve 10 filhos e que isso o levou a assumir uma grande responsabilidade em dar estado conveniente ao lugar de qualidade que possuíam sem deixar de ouvir o desejo de cada um. Ele tinha ainda duas filhas, Luiza de Freytas Bacellar e Maria do Carmo, que manifestavam o desejo de seguir o estado de religiosas, o que o deixava tranquilo, por haver conveniência para a reclusão 
delas na Vila de Guimarães, lugar onde havia ficado parte das rendas de seu pai e ainda residiam primas já recolhidas que poderiam assisti-las e educá-las. ${ }^{31} \mathrm{~A}$ articulação de interesses entre Pernambuco e a Vila de Guimarães é perfeita; há a conveniência de dar estado a duas filhas, com rendas produzidas em Portugal por uma parcela da família que ficou no Reino. Não haveria sangria nos bens existentes na colônia, as moças receberiam uma dotação e estariam protegidas por parentas próximas já enclausuradas no convento almejado. Fecha-se um círculo de interesses dentro da família.

Mais elucidativo do que o depoimento do pai é o do governador que, favorável à licença, ainda argumentou que, sendo o suplicante um homem limpo não podia casar todos os filhos. A carta atribuída às mocinhas, então com 13 e oito anos, ratifica as condições que tinha a família para dar estado a ambas, apesar de ser uma família de extensa prole. Segue um trecho dos argumentos atribuídos às meninas:

[...] Têm escolhido o estado de religiosas por ser o dito estado de seu gênio, e natural inclinação: e como o dito seu pai por se achar com grande carga de dez filhos e filhas tem conveniência de lhes dar o estado no serviço de Deus de religiosas Dominicanas [...] que no dito convento tem as suplicantes suas tias e primas as quais o dito seu pai tem favorecido com dotes e tenças das quais podem se aproveitar e viver [...].32

Embora na correspondência encaminhada ao reino seja mencionada a natural inclinação das menores ao estado religioso, é-nos impossível imaginar que meninas de 13 e oito anos pudessem ter alguma ideia clara do que fazer com o resto de suas vidas. Sem contar que elas deixam explícita a dificuldade que o genitor tem com tantos filhos e, nesse contexto, a "conveniência" de fazê-las freiras. Não sabemos qual foi o destino do restante da prole de Manoel Alves Ferreira. É provável que as meninas que aparecem nesse processo fossem as mais novas, tendo já sido exaurida boa parte dos bens da família concedendo dotes. Acreditamos, porém, que, motivadas pelas naturais dificuldades de casar filhas, desde cedo, as famílias dessem uma educação que encaminhasse uma parte da prole para a condição religiosa. Segundo EManoel Araújo, as meninas recebiam em casa uma educação especial, que as habilitava ao universo religioso: além do

\footnotetext{
${ }^{31}$ AHU - Avulsos de Pernambuco - Cx. 49, Doc. 4387 - 7/5/1736.

32 ARAÚJO, EManoel. Teatro dos vícios: transgressão e transigência na sociedade urbana colonial. Rio de Janeiro: José Olympio, 1997. p. 258.
} 
costurar e bordar, ler, escrever e contar, aprendiam, também, latim e música. ${ }^{33}$ Portanto, a decisão de ir para o convento ou recolhimento não devia abalar as moças, pois muitas já haviam sido preparadas para isso, salvo em situações especiais, quando o enclausuramento dava-se por castigo.

Os casamentos indesejáveis com homens, às vezes, mais velhos 30 ou 40 anos foram, em muitos casos, agentes estimuladores para a opção claustral, mesmo porque a vida intramuros não era das mais monótonas: as festas religiosas, os encontros com amigos e admiradores, os namoros nos locutórios e parlatórios promoveram uma dinâmica muito maior para a vida das que estavam enclausuradas no convento do que no lar. ${ }^{34}$ Seguir a vida religiosa era, portanto, uma opção natural, para ambos os sexos, no mundo português setecentista. Segundo Suzanne Chantal: "Ia-se para o convento como para uma entrevista de amor, qualquer que fosse a ordem escolhida era muito raro o respeito pelas regras austeras ou mesmo pelo hábito. Entrava-se para o convento para ali se cantar no coro, fazer doces e receber visitas." 35

O cronista Domingos Loreto Couto faz referências a algumas pernambucanas ilustres que se recolheram no Reino no século XVII. Ele cita Ângela do Sacramento e Margarida da Natividade, ambas nascidas em Juriçaca, no Cabo de Santo Agostinho, filhas do senhor de engenho D. Luiz de Souza Henriques e de Catarina Barreto. Em princípio, foram recolhidas ao Mosteiro de Santa Marta, em Lisboa, para, logo depois, serem transferidas para o Convento de Santa Clara, em Coimbra. Anos depois, a sobrinha Margarida de Souza professou na mesma casa, tornando-se abadessa em 1729. No Convento de Santa Clara de Lisboa, estiveram reclusas Úrsula, Maria e Paula, naturais de Olinda e filhas de Antonio Cavalcanti de Albuquerque e Inez de Góes. Também Mariana de Albuquerque, filha de Antonio de Albuquerque Coelha e de Inez Maria Coelha. Para outro convento em Portugal, como o da ordem cisterciense em Lorvão, foi Bernarda

\footnotetext{
${ }^{33}$ Para proceder a um aprofundamento desse tema, ver, entre outros autores: MIRANDA, Ana. Que seja em segredo. São Paulo: Companhia das Letras, 1999; NASCIMENTO, Anna Amélia Vieira do. Patriarcado e religião: as enclausuradas clarissas do Convento do Desterro da Bahia 1677-1890. Bahia: Conselho Estadual de Cultura, 1994; PINHO, Wanderley. Salão e damas do Segundo Reinado. São Paulo: Livraria Martins, 1959.

${ }^{34}$ CHANTAL, Suzanne. A vida cotidiana em Portugal no tempo do terremoto. Lisboa: Livro do Brasil, 1965. p. 44.

${ }^{35}$ Idem.
} 
Maria de Albuquerque, e, para o de Nossa Senhora da Conceição da Luz, em Lisboa, foram Luiza de Albuquerque, Julia Maria do Menino Jesus e Tereza do Sacramento. Para o Convento de Santa Clara de Angra, capital da Ilha Terceira, em 1689, foi Agueda de Jesus Maria, nascida em Recife e filha de Domingos da Costa Araújo e de Tereza Gomes de Figueiredo. ${ }^{36}$

Também órfãs cruzaram o Atlântico em busca de estado adequado à sua condição. Maria Clara do Nascimento e Joana Madalena da Glória eram filhas de José de Mendonça Figueira, naturais de Recife, que, nos idos de 1740, ficaram órfãs. Receberam como tutor o coronel Manoel de Souza Teixeira, que lhes resolveu dar o estado de religiosas no Convento de Santana, da Ordem Terceira Regular, na cidade de Lisboa. Foi paga a quantia de mil cruzados a cada uma, para que se estabelecessem na clausura. Na sequência, morreu-lhes o tutor. Afastado o protetor, a condição das órfãs recolhidas tornou-se periclitante, pois teriam, segundo sua petição, ainda cada uma direito a 20 mil de legítimas, as quais desejavam que fossem colocadas a juros e pagas em forma de tenças para seu sustento. Nada mais havia sido pago além da quantia inicial para instalação. É provável que o juiz de órfãos estivesse administrando o patrimônio das solicitantes. Levando em consideração o grande volume de denúncias ao Conselho Ultramarino sobre a malversação e até apropriação do patrimônio dos órfãos por esses juízes, é provável que elas nunca tenham sido atendidas em seu pleito. ${ }^{37}$

Com base nas petições encaminhadas ao Arquivo Histórico Ultramarino, sabemos das famílias que encaminharam filhas para as instituições de clausura no Reino, como as filhas de Manoel Alves Ferreira, que foram encaminhadas para Guimarães, entre outras, ao longo do XVIII. Destacamos as filhas de José Vaz Salgado, homem de posses, comerciante e militar, que nasceu em 1697 no Conselho, de Fafe, integrante do distrito de Braga no norte de Portugal. Foi familiar do Santo Ofício e militar das tropas auxiliares do Terço de Pernambuco, tendo se casado com Tereza Maria José, filha do boticário Bento Pereira, que também foi familiar do Santo Ofício. No decorrer de sua vida, José Vaz Salgado tornou-se membro da vereança recifense e integrante das irmandades da Santa Casa de Misericórdia e do Santíssimo Sacramento, instituições que abrigaram a nata da sociedade de então. Em 1746, requereu a provisão para recolher suas filhas, Ana, Maria Tereza

\footnotetext{
${ }^{36}$ COUTO. Op. cit., p. 147; e ALMEIDA. Op. cit., p. 102-109.

${ }^{37}$ AHU - Avulsos de Pernambuco - Cx. 56, Doc. 4874, 27/12/1740.
} 
e Hipólita, no Reino. No entanto, a investigação de seu espólio demonstra que, embora tenha requisitado a clausura para as três moças, só uma recolheu-se, pois as outras duas depois participam da partilha de seus bens, apresentando-se apenas Maria Tereza como religiosa. Não é de todo impossível que as três tenham sido enclausuradas, mas depois a família resolveu casá-las, tendo sido decidido que apenas uma ficaria na clausura, e as razões para essa decisão são múltiplas, inclusive a vocação de Tereza. ${ }^{38}$ Nos pedidos, só alguns tiveram registradas as idades. Muitas eram muito jovens, o que permitia às famílias voltarem atrás na questão do casamento. ${ }^{39}$

\section{Considerações finais}

Pela documentação consultada, percebeu-se, também, que mulheres foram abandonadas nos conventos do Reino; no entanto, esse sucedido não invalida o fato de as famílias terem tido preocupação e cuidado com sua prole feminina. Sabemos que é impossível controlar todas as variantes que podem incidir sobre as pessoas, mesmo as que amamos, durante sua existência. Entre as causas das penúrias sofridas por recolhidas no além-mar consideramos como a principal a morte de parentes mais próximos, como pais, irmãos e tutores idôneos na administração do patrimônio de seus protegidos. Mas as evidências também apontam para o fato de que muitas tiveram mesmo de amargar o desamor e o desinteresse de seus parentes e consortes.

Assim, pelos exemplos apresentados, fica esclarecido que situações as mais diversas impuseram a alternativa da clausura; que os recolhimentos e conventos eretos nas conquistas foram vistos como um prêmio, pois deram solução a problemas de ordem econômica, moral e afetivos; que a reprodução do modelo feminino português entre os membros da nobreza da terra pode ser lida como um esforço de integração à realidade metropolitana, mas acabou estimulando confrontos que obrigaram a novas formas de negociação.

\footnotetext{
${ }^{38}$ AHU - Avulsos de Pernambuco - Cx 62, Doc. 5345 - 21/3/1746. Ver, também: SOUZA, George Félix Cabral. Elite e ejercicio de poder en el Brasil colonial: la Câmara Municipal de Recife (17101822). Tese (Doutorado em História) - Universidad de Salamanca, 2007.

${ }^{39}$ Para o aprofundamento dessa questão, ver o já citado O sexo devoto..., p. 106-107.
} 
